\title{
The Pattern of Consumption of Fruits and Vegetables by Undergraduate Students: A Case Study
}

\author{
T. Perera and T. Madhujith ${ }^{1^{*}}$ \\ Postgraduate Institute of Agriculture \\ University of Peradeniya \\ Sri Lanka
}

\begin{abstract}
Dietary patterns rich in high fruits and vegetables intake are associated with a myriad of health benefits. Dietary habits of young adults is in limelight, as this group is in transition from adolescence to adulthood and are potential to influence the health status of next generation. The purpose of this study was to explore the fruit and vegetable consumption behavior of undergraduate students of the University of Peradeniya. The specific objectives were to (i) identify the fruit and vegetable consumption pattern of the cohort (ii) identify the knowledge and attitudes of students over fruit and vegetable consumption as perceived facilitators and barriers, and (iii) establish relationships among different factors influencing fruit and vegetable consumption pattern of undergraduate students. The study was carried out with 90 students from the Faculties of Agriculture, Medicine and Engineering. Respondents were instructed to indicate the frequency and portion size representing their usual diet using a Food Frequency Questionnaire. Data were analyzed using probit analysis to identify the factors affecting dietary consumption of fruits and vegetables. It was observed that the most frequently consumed fruits by the study cohort were banana, papaya, mango, orange and pineapple and the vegetables were beans, dhal, carrot, potato, leeks, pumpkin, Gotukola and Mukunuwenna. The mean fruit and vegetable consumption per day was $267 \mathrm{~g}$ which is far less than the recommended quantity for the particular age group. Regression results revealed that the faculty, religion and the academic year did not significantly ( $p>0.05)$ affect the recommended intake. However, gender, income, taboos and knowledge score have shown significant effect on fruit and vegetable consumption among undergraduate students tested. Further, it was revealed that a high proportion of the students were unaware of the health benefits of consumption of fruits and vegetables.
\end{abstract}

Key words: Food frequency questionnaire, fruits, recommended intake, undergraduate students, vegetables

\section{INTRODUCTION}

Regular consumption of fruits and vegetables is associated with a myriad of health benefits. Maintenance of health of young adults in a country is of paramount importance. Young adults aged between 18 and 24 years are in a stage of life which often leads the first chance to make their own food choices. Moreover, this is the age at which many students commence tertiary education by entering university. In nutritional studies the eating behaviours and food choice of university students are determined by an interaction of various different factors.

Department of Food Science and Technology, Faculty of Agriculture, University of Peradeniya, Peradeniya,

Sri Lanka

Author for correspondence: madujith@yahoo.com 
These are biological (changing energy demands and weight change) and socio-cultural (availability, food prices, and culture) factors (Liming, 2004).

Most fruits and vegetables are low in calories and fat. However, provide fibre and a range of vitamins including vitamins $\mathrm{A}$ and $\mathrm{C}$, folic acid and an array of phytochemicals which are implicated in beneficial health effects. There is mounting evidence to the effect that bioactives present in fruits and vegetables help protecting against a number of diseases such as coronary heart diseases, hypertension and cancers (British Dietetic Association, 2011). Thus, the general advice is to consume significant proportions of fruits and vegetables to ensure the protection from Non Communicable Diseases (NCDs). In this context, World Health Organization (WHO) has set standards with respect to consumption of fruits and vegetables by recommending a minimum of $400 \mathrm{~g}$ per day. Currently, NCDs have overtaken communicable diseases and are now the leading causes of mortality, morbidity, and disability. In 2001 NCDs accounted for $71 \%$ of all deaths in Sri Lanka (WHO, 2011). In 1995, more than $20 \%$ of cancers in Sri Lanka were attributable to inadequate fruit and vegetable intake and it has predicted that this value will further go up in the future. According to the FAO food balance sheets in 2005, the per capita fruit and vegetable consumptions were $77 \mathrm{~g}$ and $70 \mathrm{~g}$, respectively, which are much lower than the recommended quantities by WHO (FAO, 2005). According to the consumer finances and socioeconomic survey, vegetable consumption is higher than that of fruit consumption. Of a variety of vegetables available at local or imported category, beans, brinjal, cabbage, pumpkin, carrot and beet root are the most frequently consumed vegetables. Among the leafy vegetables, Mukunuwanna and Gotukola are the most consumed. The fruit consumption is generally very low. Jak fruit, banana, grapes and mangoes are found to be the highest consumed fruits (Consumer finances and socioeconomic survey, 2003/04).

Schroeter et al. (2007) investigated the fruit and vegetable consumption among college students in Arkansas and determined that demographics, lifestyle, knowledge on health and food culture were significantly related to the consumption behaviour. A research carried out in Turkey to investigate the fruit and vegetable consumption among university students discussed the significant gender differences related to the consumption of fruits and vegetables (Unusan, 2004). According to the findings, female students were more likely to eat vegetables during lunch and dinner and they prefer eating a fruit instead of a dessert at lunch or dinner and during breakfast. Compared to the female students, male students were less likely to eat fruits. Adults earning low income consumed a smaller variety of fruits and vegetables than the high income counterparts. Fruit and vegetable variety did not vary by income among adolescents. Adults earning low income expressed less desire to increase their fruit and vegetable consumption due to price and storage barriers. A study was carried out by Neumark-Sztainer et al. in 2006 to investigate fruit and vegetable consumption among American adolescent population. The authors identified that the strongest correlates of fruit and vegetable intakes were home availability of vegetables and the taste preferences of fruits and vegetables. Correlates of home availability included social support for healthy eating, family meal patterns, family food security, and socio-economic status. Correlates of taste preferences included health/nutrition attitudes and home availability of fruits/vegetables. A test of interaction effects indicated that when home availability of fruits/vegetables was low, intake patterns did not differ, regardless of taste preferences. In contrast, even when taste preferences for fruits and vegetables were low, if they were available, intake increased.

In this backdrop, the objectives of this study were to analyze the fruit and vegetables consumption behaviour among a cohort of undergraduate students at University of Peradeniya, Sri Lanka. The specific objectives were to determine fruit and vegetable 
consumption pattern among the cohort, to identify the knowledge and attitudes of students over fruit and vegetable consumption as perceived facilitators and barriers and to establish a relationship between different factors influencing consumption behavior of fruits and vegetables.

\section{MATERIALS AND METHODS}

A self-administered semi-quantitative Food Frequency Questionnaire (FFQ) was used in the study to estimate the usual daily fruit and vegetables intake of the respondents. FFQs were distributed among undergraduate students at the Faculties of Agriculture, Medicine and Engineering of University of Peradeniya. The faculties were selected randomly and 30 students from each faculty were given the questionnaires based on purposive selection. The systematic sampling method was adopted. Respondents were instructed to indicate the frequency and portion size categories that best fit their usual diet with in a week. Apart from information on consumption a separate section on demographic characteristics, their knowledge and attitudes over the consumption decision was assessed to obtain an idea on their perceived benefits and barriers in relation to fruit and vegetable consumption.

\section{Analytical framework}

Data were analyzed using descriptive statistics. A knowledge index was compiled by assigning values ranging from +1 to -1 for each of the questions tested according to the current recommendations published by WHO. The factors influencing the fruit and vegetable consumption were investigated using a probit analysis.

The following statistical model was specified to establish the causal relationship between the fruit and vegetable consumption values with respect to socio-demographic characteristics, knowledge and attitudes of respondents. Dependent variable (Y) was the quantity of fruits and vegetables consumed within a day where 0 was given if any student is eating fruits and vegetables less than $400 \mathrm{~g}$ /day as recommended by WHO and 1 was given otherwise.

$$
Y=\beta_{0}+\beta_{1} X+\beta_{2} I+\beta_{3} Z
$$

Where,

$$
\begin{array}{lll}
Y & = & \text { Fruit and vegetable consumption } \\
X & = & \text { Socio-demographic characteristics } \\
I & = & \text { Knowledge on fruit and vegetable consumption } \\
Z & = & \text { Attitude characteristics }
\end{array}
$$

\section{RESULTS AND DISCUSSION}

\section{General characteristics of the study sample}

The sample consisted of respondents with equal educational backgrounds. Among 90 students tested, $44(48.90 \%)$ respondents were males while $46(51.50 \%)$ were females. There were students representing first, second, third and fourth years of their academic programmes while the majority of the students were in their fourth year of study $(35.60 \%)$. Age profile of the respondents ranged from 20 to 26 years and $31 \%$ students was found to be 
24 years old. The students in the sample represented different ethnic groups, such as Sinhala $(83.30 \%)$, Tamil $(13.30 \%)$ and Muslim (1.10\%). Approximately half of the population had more than Rs 25000.00 of family income per month (Table 1). On average a student received an income of Rs 7885.55 either from family or other sources. Most of the students were from Western, Southern and Central provinces while a small fraction was from Sabaragamuwa, Uva, Eastern, Wayamba and North Central provinces. Fig. 1 and Table 2 depict the food choice behaviour and status of nutritional knowledge of respondents.

Table 1. Family income distribution of the sample

\begin{tabular}{lcc}
\hline $\begin{array}{l}\text { Income Category } \\
\text { (Rs/month) }\end{array}$ & Frequency & Percentage \\
\hline$<$ Rs $10,000.00$ & 14 & 15.6 \\
Rs $10,000-25,000$ & 31 & 34.4 \\
$>$ Rs $25,000.00$ & 45 & 50.0 \\
\hline
\end{tabular}

Tale 2. Self-rated nutritional knowledge of the respondents

\begin{tabular}{lcc}
\hline Category & Frequency & Percentage \\
\hline Poor & - & - \\
Fair & 16 & 17.80 \\
Average & 45 & 50.00 \\
Above Average & 28 & 31.10 \\
Excellent & 1 & 1.10 \\
\hline
\end{tabular}

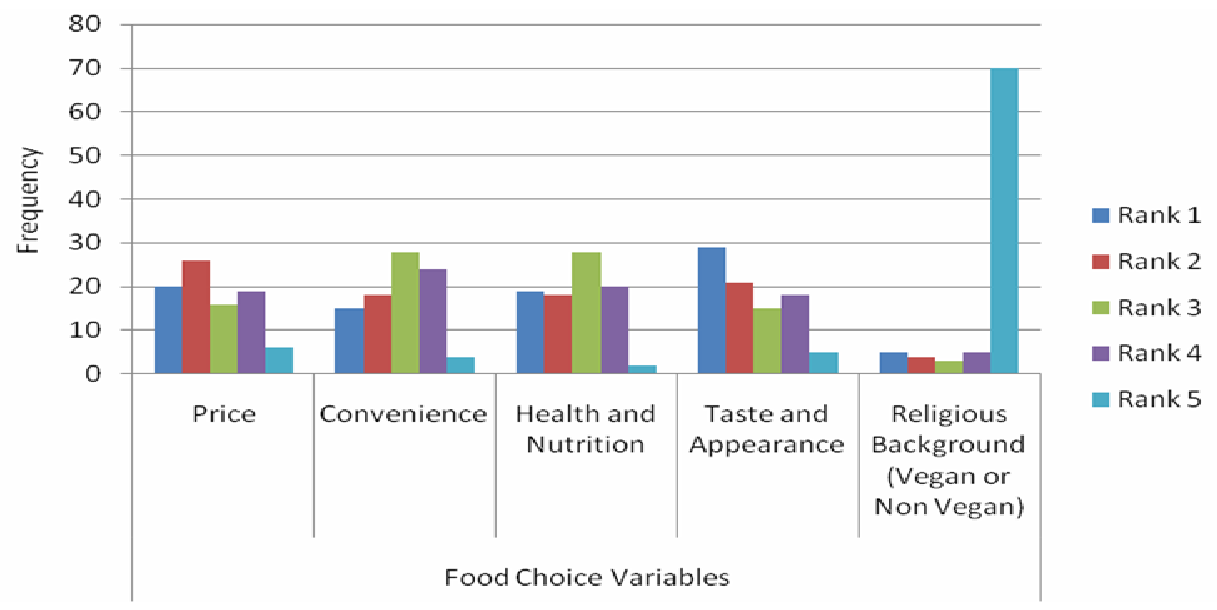

Fig. 1. Food choice behaviour of the sample

Rank 1 was the most important variable while rank 5 was the least important.

According to the Fig. 1, most of the respondents have rated taste and appearance as their number one choice in food selection. As depicted in Table 2, 45\% percent has self rated as their nutritional knowledge to be average. However, no one has rated that they are in the category of poor knowledge. 


\section{Fruit and vegetable consumption profile}

Tables 3 and 4 depict the fruit and vegetable consumption behaviour of university students.

Table 3. Fruit consumption frequency profile

\begin{tabular}{lcccc}
\hline Fruit & $\begin{array}{c}\text { 1 day } \\
\text { per week }\end{array}$ & $\begin{array}{c}\mathbf{2 - 3} \text { days } \\
\text { per week }\end{array}$ & $\begin{array}{c}\text { 5-6 days } \\
\text { per week }\end{array}$ & $\begin{array}{c}\text { Everyday } \\
\text { in the week }\end{array}$ \\
\hline Jak Fruit & $11(12.2)$ & & & \\
Banana & $23(25.6)$ & $32(35.6)$ & $10(11.1)$ & $3(3.3)$ \\
Grapes & $7(7.8)$ & $1(1.1)$ & & \\
Mangoes & $20(22.2)$ & $10(11.1)$ & $2(2.2)$ & \\
Papaw & $22(24.4)$ & $9(10.0)$ & $2(2.2)$ & \\
Apple & $15(16.7)$ & $8(8.9)$ & & \\
Pineapple & $19(21.1)$ & $5(5.6)$ & & \\
Guava & $9(10.0)$ & $1(1.1)$ & & \\
Avocado & $11(12.2)$ & $2(2.2)$ & & \\
Wood apple & $7(0.1)$ & $1(0.0)$ & & \\
Oranges/mandarin & $20(22.2)$ & $12(13.3)$ & & \\
Beli & $3(3.3)$ & & & \\
Melon & $6(6.7)$ & $2(2.2)$ & & \\
Pomegranate & $3(3.3)$ & & & \\
Passion fruit & $9(10.0)$ & $3(3.3)$ & & \\
Lovi & $1(1.1)$ & & & \\
Veralu & $8(8.9)$ & & & \\
Jambu (rose apple) & $14(15.6)$ & $9(10.0)$ & & \\
Any tinned fruit & $3(3.3)$ & $1(1.1)$ & & \\
Dates & $5(5.6)$ & $3(3.3)$ & & \\
Sultanas & $1(1.1)$ & $1(1.1)$ & & \\
\hline
\end{tabular}

The values in parenthesis are percentages

According to Table 3, the most-consumed fruits during the week were banana (75.56\%), papaya $(36.76 \%)$, mango $(35.56 \%)$, oranges $(35.45 \%)$ and pineapple $(26.67 \%)$. Besides, apple, rose apple (Jambu) and avocado were also consumed while grapes, dates, Sultanas and other dried fruit products were consumed less frequently. Most of the time a majority had consumed at least one fruit during a day of the week rather than consuming a fruit everyday.

The most-consumed vegetables included beans and dhal as pulses, carrot, potato and leeks as upcountry vegetables, pumpkin and jak as tropical vegetables and Gotukola and Mukunuwenna as leafy vegetables. Most of the vegetables are consumed either a day or 2-4 days in the week whereas around $27 \%$ of this cohort has consumed dhal on a daily basis. However, other vegetables such as brinjals, cabbage, bitter gourd, snake gourd are consumed very occasionally (Table 4).

Table 5 shows the mean consumption of fruits and vegetables by the students. At least 3 fruits and 7 vegetable types were consumed by the students including only a half a cup of fruit salad and one fruit juice. The amount consumed during the week was calculated and the values were divided by seven. 
Perera and Madhujith

Table 4. Vegetable consumption frequency profile

\begin{tabular}{lcccc}
\hline Vegetable & $\begin{array}{c}\mathbf{1} \text { day } \\
\text { per week }\end{array}$ & $\begin{array}{c}\mathbf{2 - 3} \text { days } \\
\text { per week }\end{array}$ & $\begin{array}{c}\mathbf{5 - 6} \text { days } \\
\text { per week }\end{array}$ & $\begin{array}{c}\text { Everyday } \\
\text { in the week }\end{array}$ \\
\hline Pumpkin & $32(35.6)$ & $16(17.8)$ & & $1(1.1)$ \\
Leeks & $27(30.0)$ & $22(24.4)$ & $2(2.2)$ & $1(1.1)$ \\
Jak & $16(17.8)$ & $1(1.1)$ & & \\
Polos & $23(25.6)$ & $5(5.6)$ & & \\
Dhal & $3(3.3)$ & $25(27.8)$ & $18(20.0)$ & $27(30.0)$ \\
Beans & $12(13.3)$ & $46(51.1)$ & $7(7.8)$ & $1(1.1)$ \\
Winged bean & $9(10.0)$ & $4(4.4)$ & & $1(1.1)$ \\
Carrot & $18(20.0)$ & $39(43.3)$ & $6(6.7)$ & $2(2.2)$ \\
Potato & $22(24.4)$ & $35(38.9)$ & $6(6.7)$ & $1(1.1)$ \\
Gotukola & $26(28.9)$ & $21(23.3)$ & $5(5.6)$ & \\
Thampala & $6(6.7)$ & $2(2.2)$ & $1(1.1)$ & \\
Mukunuwenna & $13(14.4)$ & $11(12.2)$ & $3(3.3)$ & \\
Katurumurunga & $8(8.9)$ & $5(5.6)$ & $1(1.1)$ & \\
Brinjal & $4(4.4)$ & $8(8.9)$ & & \\
Okra & $7(7.8)$ & $3(3.3)$ & & \\
Cabbage & $8(8.9)$ & $5(5.6)$ & $1(1.11)$ & \\
Soy & $5(5.6)$ & $1(1.1)$ & & \\
Bitter gourd & $3(3.3)$ & $1(1.1)$ & & \\
Cassava & $1(1.1)$ & & & \\
Banana blossoms & $1(1.1)$ & $1(1.1)$ & & \\
Beet root & $6(6.7)$ & $3(3.3)$ & & \\
Snake gourd & $2(2.2)$ & $1(1.1)$ & & \\
Tomato & $3(3.3)$ & $1(1.1)$ & & \\
Ash plantain & $1(1.1)$ & & & \\
Spinach & & $1(1.1)$ & & \\
\hline
\end{tabular}

The values in parenthesis are percentages

Table 5. Mean consumption of fruits, fruit products and vegetables by students

\begin{tabular}{lcc}
\hline Fruit/Vegetable & $\begin{array}{c}\text { Mean } \\
\text { (Number) }\end{array}$ & Standard Deviation \\
\hline Fruits & 3.30 & 2.08 \\
Fruit juices & 1.22 & 1.12 \\
Fruit salads & 0.48 & 0.50 \\
Vegetables & 6.87 & 2.57 \\
\hline
\end{tabular}

The average vegetable consumption was quite higher while fruit consumption (inclusive of salads and juices) was rather low (Table 6). The mean consumption of fruits and vegetables by sample remained $267.75 \mathrm{~g}$ which was slightly higher than the half of the recommended quantity for daily consumption. There were 14 respondents who had consumed fruits and vegetables more than $400 \mathrm{~g}$ per day. The quantity of fruits and vegetables consumed ranged from 67 to $715 \mathrm{~g} /$ day. 
Table 6. Fruit and vegetable consumption quantity profile/day

\begin{tabular}{lcc}
\hline Type & $\begin{array}{c}\text { Mean } \\
(\mathbf{g})\end{array}$ & Standard Deviation \\
\hline Fruits & 98.30 & 95.34 \\
Fruit juices & 35.95 & 44.93 \\
Fruit salads & 6.48 & 08.72 \\
Vegetables & 127.01 & 80.91 \\
Total & 267.75 & 123.57 \\
\hline
\end{tabular}

\section{Knowledge and attitude profile}

The knowledge and attitudes on towards fruit and vegetable consumption was determined based on the responses to a questionnaire. Table 7 depicts knowledge profile of the students pertaining to the consumption of fruits and vegetables.

Table 7. Knowledge profile

\begin{tabular}{|c|c|c|c|}
\hline \multirow[b]{2}{*}{ Statement (Knowledge on) } & \multicolumn{3}{|c|}{ Answer } \\
\hline & Yes & No & $\begin{array}{c}\text { Do not } \\
\text { know/ No } \\
\text { response }\end{array}$ \\
\hline WHO recommended amount to be consumed & - & $49(54.5)$ & $41(45.6)$ \\
\hline "5 a day" slogan on to fruits and vegetables & $\begin{array}{l}7 \\
(7.8)\end{array}$ & $77(85.5)$ & $\begin{array}{l}6 \\
(6.7)\end{array}$ \\
\hline $\begin{array}{l}\text { Health benefits of consumption of fruits and } \\
\text { vegetables }\end{array}$ & $87(96.7)$ & - & $\begin{array}{l}3 \\
(3.3)\end{array}$ \\
\hline The food pyramid & $\begin{array}{l}4 \\
(4.5)\end{array}$ & $\begin{array}{l}11 \\
(12.2)\end{array}$ & $75(83.3)$ \\
\hline $\begin{array}{l}\text { Effect of cooking methods reduce the nutritional } \\
\text { quality }\end{array}$ & $84(93.3)$ & $\begin{array}{l}6 \\
(6.7)\end{array}$ & - \\
\hline $\begin{array}{l}\text { Fruits and vegetables as a good source of } \\
\text { phytochemicals }\end{array}$ & 78( & $\begin{array}{l}6 \\
(6.7)\end{array}$ & $\begin{array}{l}6 \\
(6.7)\end{array}$ \\
\hline Fruits and vegetables are high caloric food & $37(41.1)$ & $28(31.1)$ & $25(27.8)$ \\
\hline $\begin{array}{l}\text { At least a one fruit and vegetable containing } \\
\text { vitamin A }\end{array}$ & $36(40.0)$ & $\begin{array}{l}3 \\
(3.3)\end{array}$ & $51(56.7)$ \\
\hline $\begin{array}{l}\text { At least one fruit and vegetable containing } \\
\text { vitamin B }\end{array}$ & $5(5.6)$ & - & $85(94.4)$ \\
\hline $\begin{array}{l}\text { At least one fruit and vegetable containing } \\
\text { vitamin } \mathrm{C}\end{array}$ & $62(68.9)$ & - & $28(31.1)$ \\
\hline At least one fruit and vegetable containing iron & $34(37.8)$ & - & $56(62.2)$ \\
\hline $\begin{array}{l}\text { At least one fruit and vegetable containing } \\
\text { potassium }\end{array}$ & $10(11.1)$ & - & $80(88.9)$ \\
\hline
\end{tabular}

The values in parenthesis are percentages

Fig. 2 provides self-rated reasons as to why people should eat fruits and vegetables. Most of the respondents have rated health aspects such as prevention of diseases and staying healthy while some stated that nutritional considerations such as obtaining vitamins and minerals are most important. Regarding the attitudes on fruit and vegetable consumption $60 \%$ of students indicated that they would like to consume only fruits while $35.55 \%$ liked to have both fruits 
and vegetables while only $2.23 \%$ liked only to consume vegetables. A sizable fraction did not like to consume neither fruit nor vegetable containing meal during the morning and the similar pattern was observed in snack times as well. However, a substantial number agreed that they would like to have a vegetable on a side dish and a fruit as a dessert. Nearly $49 \%$ respondents believed in food taboos related to fruit and vegetable consumption. This is quite high number when the level of education of the respondents is considered. This phenomenon explains the embedded cultural and religious influences on food selections of individuals. Fig. 3 summarizes different factors respondents have rated as barriers in their fruit and vegetable consumption.

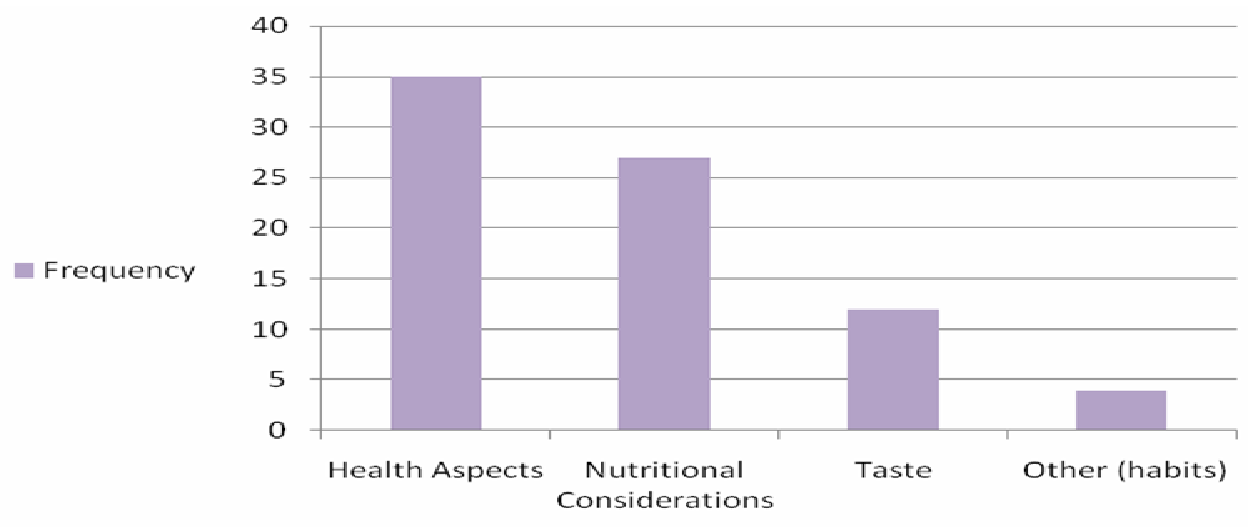

Fig. 2. Self-rated most important reasons to eat fruits and vegetables

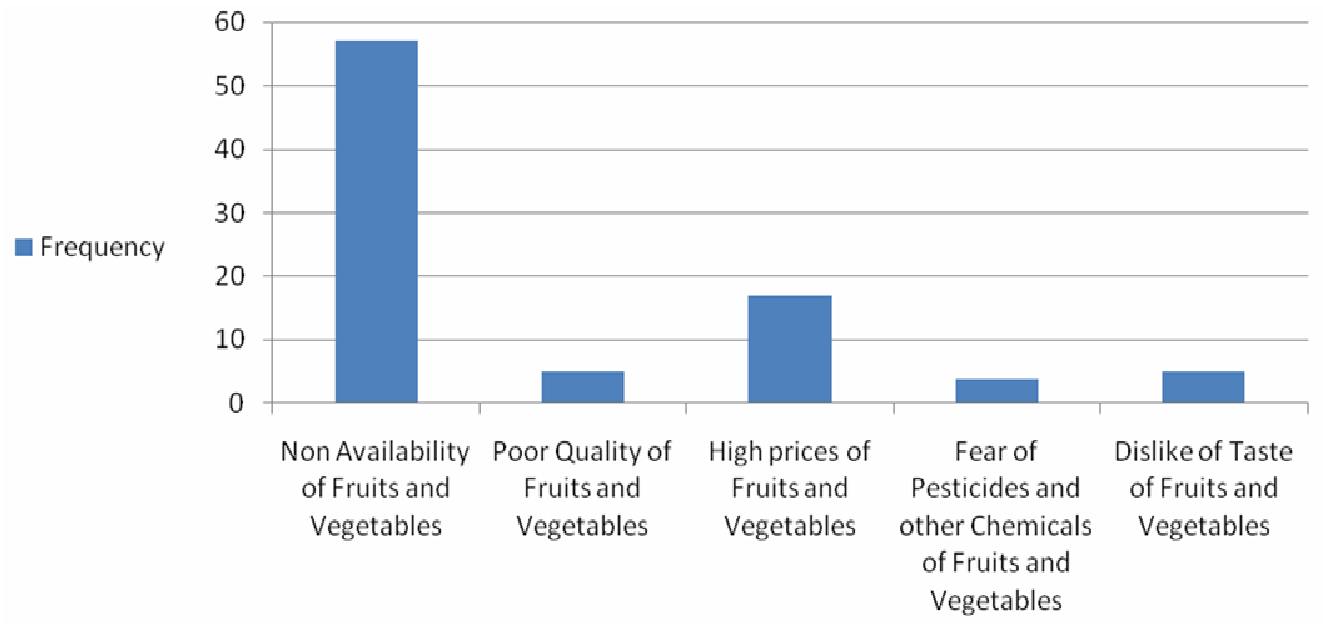

Fig. 3. Barriers for fruit and vegetable consumption

Non availability of fruits and vegetables at the proximity to students' residence was identified as the most important barrier. Nearly $83.4 \%$ stated that the place of residence influenced the consumption behaviour. Similarly, when they were asked whether they tend to eat different quantity of fruits and vegetables when they eat out $61.2 \%$ stated they eat less while $22.3 \%$ stated they eat more. Table 8 demonstrates suggestions made by students in order to enhance their fruit and vegetable consumption on a regular basis. 
Table 8. Remedies that the respondent think may help consume fruits and vegetables on a daily basis

\begin{tabular}{lcc}
\hline Factor & Frequency & Percentage \\
\hline $\begin{array}{l}\text { Availability of fruits and vegetables around resident } \\
\text { halls and close proximities }\end{array}$ & 36 & 40.0 \\
$\begin{array}{l}\text { Availability of quality fruits and vegetables } \\
\text { Introduction of a fruit and vegetable subsidy for } \\
\text { university students }\end{array}$ & 5 & 5.6 \\
$\begin{array}{l}\text { Introduction of a convenient and novel fruit and } \\
\text { vegetable based products }\end{array}$ & 7 & 36.7 \\
$\begin{array}{l}\text { Improving the palatability and quality of food in hall } \\
\text { of residence. }\end{array}$ & 5 & 7.8 \\
$\begin{array}{l}\text { Promote attitude for more fruit and vegetable } \\
\text { consumption }\end{array}$ & 4 & 5.6 \\
\hline
\end{tabular}

\section{Factors affecting the quantity of fruit and vegetable consumed: the probit analysis}

The model showed a pseudo $\mathrm{R}^{2}$ of 0.5082 and was significant at 0.05 level (Prob $>F \quad 0.002$ ). Probit results indicated that gender, income, total number of fruits and vegetables consumed, taboo beliefs and knowledge score had a significant relationship with fruit and vegetable consumption. The modem was tested for heteroscedasticity as the data were cross sectional (Table 9).

Table 9. Coefficient estimates of the probit model for fruit and vegetable consumption

\begin{tabular}{|c|c|c|c|c|}
\hline Variable & Category & Coefficients & $\begin{array}{l}\text { Marginal } \\
\text { probability }\end{array}$ & $\begin{array}{c}\text { Standard } \\
\text { error }\end{array}$ \\
\hline $\begin{array}{l}\text { Faculty of } \\
\text { Agriculture }\end{array}$ & Dummy & -0.8679 & -0.0462 & 0.6322 \\
\hline $\begin{array}{l}\text { Faculty of } \\
\text { Engineering }\end{array}$ & Dummy & 0.6670 & 0.0550 & 0.9382 \\
\hline Academic year & Year & -0.0691 & -0.0044 & 0.3846 \\
\hline $\begin{array}{l}\text { Gender (Male (1), } \\
\text { Female - }(0))\end{array}$ & Dummy & -0.9265 & -0.0666 & $0.4724 * *$ \\
\hline $\begin{array}{l}\text { Ethnicity } \\
\text { (Sinhala(1),Others } \\
(0))\end{array}$ & Dummy, & 0.5619 & 0.0257 & 0.5228 \\
\hline $\begin{array}{l}\text { Income of the } \\
\text { Student }\end{array}$ & $\begin{array}{l}\text { Rupees per } \\
\text { month }\end{array}$ & 0.0002 & 0.0001 & $0.0001 * * *$ \\
\hline $\begin{array}{l}\text { Taboo beliefs } \\
\text { (Yes (1), No (0)) }\end{array}$ & Dummy, & -1.4292 & -0.1182 & $0.6444 * * *$ \\
\hline $\begin{array}{l}\text { Total number of } \\
\text { fruits and } \\
\text { vegetables eaten }\end{array}$ & Number & 0.1129 & 0.0072 & $0.0672 *$ \\
\hline Knowledge score & Number & 0.3321 & 0.0210 & $0.1461 * * *$ \\
\hline Constant & & -4.2672 & & $2.2941^{*}$ \\
\hline
\end{tabular}

* Significant at 0.1 leveln-84

** Significant at 0.05 level

*** Significant at 0.01 
According to the probit regression, the variable gender showed a significant negative relationship with the probability of a student eating fruits and vegetables above $400 \mathrm{~g} /$ day reflecting that females have a more probability of consuming fruits and vegetables compared to males. Thereby, when gender changed from male to female, the likelihood of eating fruits and vegetables above $400 \mathrm{~g}$ were increased by $6.6 \%$. The monthly income received from parents or other sources had a positive significant relationship indicating more affluent students tend to eat more fruits and vegetables rather than others. The statistical association further inferred that the probability of consuming fruits and vegetables above $400 \mathrm{~g}$ will increased by $0.01 \%$ when the student are effluent.

The taboo beliefs play an important role as it represented a negative relationship with fruit and vegetable consumption over $400 \mathrm{~g} /$ day. Total number of fruits and vegetables consumed has a positive and significant relationship with more than $400 \mathrm{~g}$ daily consumption. The knowledge score also shows a positive and significant relationship with respect to fruit and vegetable consumption. This further explains that with an increase in one unit of the index, the likelihood of a student eating fruits and vegetables more than $400 \mathrm{~g}$ a day increased by $2.1 \%$. However, the faculty, academic year and ethnicity did not exhibit a statistically significant relationship with respect to fruit and vegetable consumption.

\section{CONCLUSIONS}

It was found that the most frequently consumed fruits and vegetables by the study cohort are banana, papaya, mango, oranges and pineapple, and beans, dhal, carrot, potato, leeks, pumpkin, and Gotukola and Mukunuwenna, respectively. The mean fruit and vegetable consumption per day remains $267 \mathrm{~g}$ which is far less than the WHO recommendations. Most of the students has a fair knowledge on some of the basic aspects such as health benefits of fruits and vegetables, effect of cooking and handling method on quality, among others. However, most of the students were unaware of the recommended quantity to be consumed. The faculty of study, academic year and religion did not affect the quantity of fruits and vegetables consumed while gender, income, taboos had a significant effect.

\section{REFERENCES}

British Dietetic Association (2011) Food Facts. viewed on $19^{\text {th }}$ January 2011 http://www.bda.uk.com/foodfacts/.

Consumer Finances and Socioeconomic Survey (2003/2004). Central Bank Publications, Central Bank, Sri Lanka.

FAO (2005) Food Security Statistics, Food and Agriculture Organization, viewed on $12^{\text {th }}$ January 2011 http://www.fao.org/economic/ess/food-security-statistics/en/.

Liming, L. (2004). Fruit and Vegetable Intake and Factors Influencing Intake of Adolescents: Developing the Questionnaires'. Master of Science Thesis, British Columbia University.

Neumark-Sztainer, D, Story, M, Resnick, M.D, and Blum, R.W, (2006). Correlates of Inadequate Fruit and Vegetable consumption among Adults. Journal of Preventive Medicine, vol. 25, no.5. 
Schroeder, C., Lisa, H. and Argelia, L. (2007). Fruit and Vegetable Consumption among College Students in Arkansas and Florida: Food Culture vs. Health Knowledge. International Food and Agribusiness Management Review, vol. 10, no. 3.

Unusan, N. (2004). Fruit and vegetable Consumption among Turkish Students, Journal of Vitamin Nutrition. 74, 04. 341-348.

WHO (2011). World Health Organisation accessed on $10^{\text {th }}$ January $2011,<$ www.who.int/childgrowth $>$ 